UDC 94(100):639.1.081.323

Submitted: 15.05 .2020

LBC 63.3(0)-7

Accepted: 16.06 .2020

\title{
ON THE TIME WHEN USING HUNTING BIRDS APPEARED IN TRADITIONAL CULTURES OF EURASIA ${ }^{1}$
}

\author{
Sergey I. Lukyashko \\ Don State Technical University, Rostov-on-Don, Russian Federation; \\ Federal Research Centre The Southern Scientific Centre of the Russian Academy of Sciences, \\ Rostov-on-Don, Russian Federation
}

\begin{abstract}
Absract. Introduction. The popularity of images of birds of prey in Scythian art makes us pay more attention to the place of birds of prey in the life of the Scythian world. Birds of prey were actively used in the hunting practice, and hunting with hunting birds was an elite form of hunting common in open spaces. Materials. The first information about nurseries of hunting birds belongs to ancient China of the $7^{\text {th }}$ century BC. Images of hunting birds appear on Hittite basreliefs of the $13^{\text {th }}$ century BC. They are also known in the Assyria of the time of Sargon II. Analysis. The active participation of the Scythians in political events in the Middle East allows us to assume that the Scythians are familiar with this method of hunting. In Scythian culture, there are a series of images of attacking birds, which should be seen as naturalistic sketches. Results. The abundance of bone remains of hunting birds in the cultural layers of Scythian settlements and the presence of a burial of a man with a Falcon in the materials of the Elizavetovskoe hillfort directly indicates the use of hunting birds in the South Easten European continent steppe as early as the $4^{\text {th }}$ century BC. Scythians.

Key words: hunting, hunting birds, archaeology, paleozoology, Eurasian steppe, chronology, Hittites, Assyria,

Citation. Lukyashko S.I. On the Time When Using Hunting Birds Appeared in Traditional Cultures of Eurasia. Vestnik Volgogradskogo gosudarstvennogo universiteta. Seriya 4. Istoriya. Regionovedenie. Mezhdunarodnye otnosheniya [Science Journal of Volgograd State University. History. Area Studies. International Relations], 2020, vol. 25, no. 4, pp. 113-122. (in Russian). DOI: https://doi.org/10.15688/jvolsu4.2020.4.7
\end{abstract}

УДК 94(100):639.1.081.323

Дата поступления статьи: 15.05 .2020

ББК 63.3(0)-7

Дата принятия статьи: 16.06 .2020

\section{О ВРЕМЕНИ ПОЯВЛЕНИЯ ПРАКТИКИ ИСПОЛЬЗОВАНИЯ ЛОВЧИХ ПТИЦ В ТРАДИЦИОННЫХ КУЛЬТУРАХ ЕВРАЗИИ ${ }^{1}$}

\author{
Сергей Иванович Лукьяшко \\ Донской государственный технический университет, г. Ростов-на-Дону, Российская Федерация; \\ Федеральный исследовательский центр Южный научный центр РАН, \\ г. Ростов-на-Дону, Российская Федерация
}

\footnotetext{
Аннотация. Введение. Популярность изображений хищной птицы на предметах скифского искусства заставляет повнимательней отнестись к месту хищных птиц в жизни скифского мира, которые активно использовались в охотничьей практике, и охота с ловчими птицами была элитарной формой охоты, распространенной на открытых пространствах. Материалы. Первые сведения о питомниках ловчих птиц относятся к Древнему Китаю VII в. до н. э. Изображения ловчих птиц появляются на хеттских барельефах XIII в. до н. э. Известны они и в Ассирии времени Саргона II. Анализ. Активное участие скифов в политических событиях на Ближнем Востоке допускает предположение о знакомстве скифов с этим способом охоты. В скифской культуре имеется серия изображений атакующей птицы, в которых следует видеть натуралистические зарисовки. Результатыл.Обилие костных останков ловчих птиц в культурных слоях городищ скифского времени и наличие погребения мужчины с соколом в материалах Елизаветовского городища прямо свидетельствуют об использовании ловчих птиц в Евразийской степи уже в IV в. до н. э.
} 
Ключевые слова: охота, ловчие птицы, археология, палеозоология, Евразийская степь, хронология, хетты, Ассирия, скифы.

Цитирование. Лукьяшко С. И. О времени появления практики использования ловчих птиц в традиционных культурах Евразии // Вестник Волгоградского государственного университета. Серия 4, История. Регионоведение. Международные отношения. - 2020. - Т. 25, № 4. - С. 113-122. - DOI: https://doi.org/10.15688/ jvolsu4.2020.4.7

Введение. Охота была важной составляющей жизни человека в древности и сохранилась как хобби до нашего времени. Для древних сообществ охота была и видом производственной деятельности, дополнявшим рацион питания. В Евразийской степи, населенной большим количеством разнообразных животных и птиц, этот вид деятельности был органичной составляющей жизни. Изучением охоты населения Евразии скифского времени традиционно занимались палеозоологи, которые определили состав промысловой фауны, а археологи дополнили выводы палеозоологов наблюдениями за формами ведения охоты. Были определены виды охоты: загонная, облавная, скрадывание, травление - псовая охота [5].

Однако охота с ловчими птицами не рассматривалась исследователями в применении к степным культурам раннего железного века, хотя природная среда подталкивала человека к этому виду охоты: бескрайние просторы, скорость передвижения животных, слабая изрезанность местности, своеобразная эстетика атаки птицы не могли не привлекать внимание человека. Разные виды птиц приспосабливались для добычи разной дичи. Ястребами-тетеревятниками добывали фазанов, зайцев, водоплавающую дичь. Ястребы-перепелятники брали мелкую дичь - перепелов, голубей, певчих птиц. Балобаны легко брали зайцев, дроф, имеются сведения, что они догоняли даже джейранов. Соколы брали голубей и куропаток. В Средней Азии искусные ловчие даже плохо приручавшихся луней делали ловчими птицами. Таким образом, условия для появления этого способа охоты на территории степи существовали с глубокой древности. Имеются основания предполагать этот вид охоты уже у андроновцев [6]. Позже в богатом сакском погребении Жети-Тоба VII-VI вв. до н. э. рядом с погребенным были обнаружены полные скелеты хищных птиц [3].
Древнейшие свидетельства существования такого вида охоты восходят к концу II - началу I тыс. до н. э. На Востоке это сообщения о питомниках соколов в Китае, относящиеся к началу VII в. до н. э. Но в исторической традиции сложилось представление о формировании этого способа охоты в Древней Индии, откуда он распространился в Персию и Македонию. Наивысшего развития охота достигла в Средние века. Имеются сведения, о том, что Владимир Мономах лично ухаживал за кречетами. При дворе Чингисхана соколов обслуживало 7000 семей соколятников. Соколиная охота была исключительно популярна при Московском дворе.

Материалы. На Ближнем Востоке первые свидетельства охоты с ловчими птицами (рис. 1) нашли отражение в хеттских барельефах и датируются XIII в. до н. э. Позже эта практика зарегистрирована на ассирийском барельефе из Ниневии (рис. 2) времени Саргона II (722-705 гг. до н. э.).

Первые сведения об использовании ловчих птиц в Европе связаны с Македонией и относятся к III в. до н. э.

Необычайная популярность в скифской культуре образа хищной птицы, ставшая визитной карточкой скифского искусства с первых шагов этой культуры на Северном Кавказе и в Причерноморье, заставляет внимательней отнестись к образу птицы в искусстве и значению ее в практической жизни. Не было ли здесь намека на использование птицы в охотничьей практике? Не могли ли скифы познакомиться с этой практикой во время пребывания в Передней Азии? Так выглядит общая постановка проблемы.

Археология, как наука, имеющая в качестве основного источника материальные предметы, не может строиться на предположениях, не подкрепленных источником. Но материальные предметы, отражающие этот вид охоты, изготовлялись из органичес- 
ких материалов и трудно надеяться на то, что мы сможем увидеть в археологическом комплексе клобуки, варежки, затворы или стойку для руки.

«При изучении этого вопроса исследователь сталкивается с необычайно скудной источниковой базой. С другой стороны, популярность изображений хищной птицы однозначно свидетельствует об особом отношении к хищнику и даже культе птицы в скифской культуре» $[5$, с. 67].

Анализ. В рамках скифо-сибирской общности культур известна серия художественных изображений хищных птиц, нападающих на диких животных. Нам уже приходилось обращать внимание на то, что это не просто зарисовки из мира природы, но и признаки повышенного внимания и даже любования особой эстетикой, красотой атаки хищной птицы [5, с. 67].

На поясной пряжке из Сибирской коллекции Петра I (рис. 3) представлена мифологическая сцена атаки хищной птицы на яка. В правой части изображения просматривается, по мнению С.И. Руденко, морда тигра, вцепившегося в птицу. Вся эта сцена может трактоваться как сцена борьбы за добычу, описывающая некий не дошедший до нашего времени мифологический сюжет [5, с. 67-68; 7, с. 15].

На второй пряжке хищная птица нападает по фронту на кошачьего хищника-тигра (?), держащего в зубах копытное животное (рис. 4) [2, c. 15]. В этой сцене присутствует еще один персонаж - волк-собака. И здесь мы наблюдаем сюжет борьбы за добычу. Связать ее с охотой с использованием ловчей птицы не представляется возможным. Оба эти сюжета на пряжках иллюстрируют участие в мифологии туземного населения пристального внимания к хищным птицам. Если сопоставить это внимание с известиями об использовании андроновцами ловчих птиц [6] и сообщениями греческих источников о существовании связи между местным населением и грифами, с помощью которых аримаспы добывали золото (Her.III.116), то появление этих сцен в искусстве региона не будет выглядеть экстраординарным.

В Прикубанье в 4-м Семибратнем кургане на обивке ритона изображена сцена нападения хищной птицы на зайца (рис. 5). Но уверенно утверждать, что перед нами ловчая пти- ца, мы не можем, так как дрессированная птица не будет поднимать добычу. То же самое можно сказать о бляшке с изображением большой хищной птицы с архаром в когтях из Сибирской коллекции Петра I (рис. 6).

Как уже было сказано выше, эти сцены нельзя трактовать как использование ловчей птицы, так как дрессированная птица не будет подниматься с добычей. Отметим, что сюжет нападения хищной птицы на зайца встречается в хеттском искусстве, где использование ловчих птиц документировано изображениями на барельефах.

Нет достаточных оснований, чтобы видеть в этих изображениях ловчих прирученных птиц. В специально посвященной охоте в скифском мире статье нами сделан вывод: «Возможно, здесь мы имеем некие натуралистические наблюдения древних мастеров. И можем заключить, что прямых свидетельств использования в охоте ловчих птиц в Евразийской степи пока мы не имеем» [5, с. 68].

Однако экология и природный комплекс допускают предположение о появлении первых опытов применения ловчих птиц в охоте уже в скифское время. Это предположение подкрепляется косвенными свидетельствами - наличием в культурных слоях городищ костных останков хищных птиц. Так, в Ольвии известны останки сокола-балобана [4]. Кости беркута, ястреба-перепелятника, ястреба-тетеревятника, балобана, коршуна, орлана-белохвоста обнаружены в Елизаветовском поселении на Дону. В интерпретациях этой ситуации преобладает мнение о том, что хищные птицы были объектом охоты, перья которых использовались для оперения стрел. Но вот в 2013 г. на юге Казахстана был раскопан «царский» сакский курган VII-VI вв. до н. э. Жати Тоба, где погребенного сопровождали несколько скелетов хищных птиц [3].

Кроме того, в нашем распоряжении имеется глухое упоминание о ситуации с погребением сокола-балобана вместе с мужчиной в Елизаветовском-на-Дону могильнике [1]. Ситуация позволяет видеть в птице прирученную птицу и реконструировать иной характер отношений между хищной птицей и человеком. Это пока единственные свидетельства приручения хищной птицы. От приручения к использованию в охоте длительного времени не 


\section{АРХЕОЛОГИЯ РАННЕГО ЖЕЛЕЗНОГО ВЕКА}

требуется. Между человеком и птицей устанавливаются доверительные отношения, при которых птица узнает своего хозяина и быстро обучается навыкам охоты.

Результаты. Практическое применение этого вида охоты, возможно, пришло вместе со скифами во время миграции в Восточную Европу, или скифы могли наблюдать данный вид охоты на Востоке еще во время Переднеазиатских походов. Эти наблюдения могли послужить основой развития практики использования хищных птиц, что, впрочем, не исключает самостоятельного появления этой практики в степи. Для приручения использовались птенцы, извлеченные из гнезд. А с гнездами птиц кочевник сталкивается регулярно в ходе хозяйственной деятельности.

Таким образом, ловчие птицы использовались в охоте на птиц в Евразийской степи. Кости промысловых птиц хорошо известны на поселениях [2, с. 342-345]. Объективные дан- ные позволяют уверенно датировать использование ловчих птиц в охоте в Причерноморье-Приазовье как минимум IV в. до н. э. Накопление материала может скорректировать эту дату в сторону ее углубления.

\section{ПРИМЕЧАНИЕ}

${ }^{1}$ Работа выполнена при поддержке программы фундаментальных научных исследований государственных академий наук на 2013-2020 гг. в рамках базовой темы НИР «Изучение межкультурных взаимодействий населения Нижнего Дона с древнейших времен до нового времени», № гос. регистрации 01201354248.

The work was supported by the program of fundamental scientific research of the state academies of sciences for 2013-2020 in the framework of the basic research topic "Study of intercultural interactions of the population of the Lower Don from ancient times to modern times", state registration no. 01201354248. 
С.И. Лукьяшко. О времени появления практики использования ловчих птиц в традиционных культурах Евразии

\section{ПРИЛОЖЕНИЕ}
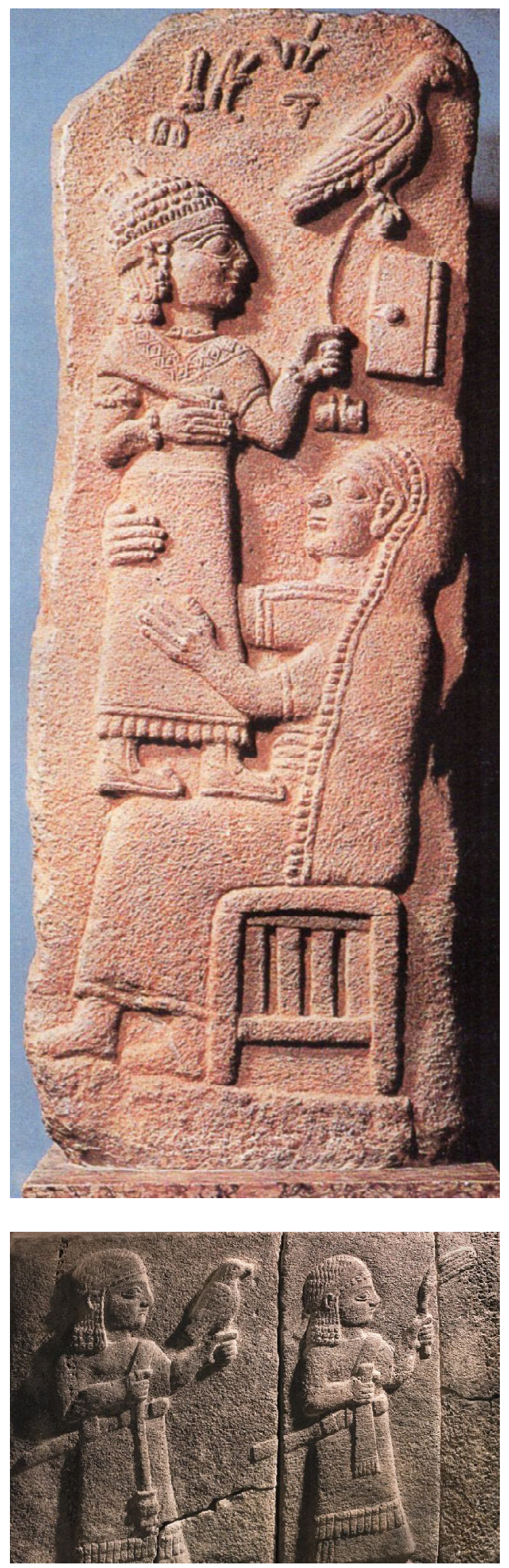

Рис. 1. Изображения ловчих птиц на хеттских барельефах

Fig. 1. Images of hunting birds on Hittite bas-reliefs 


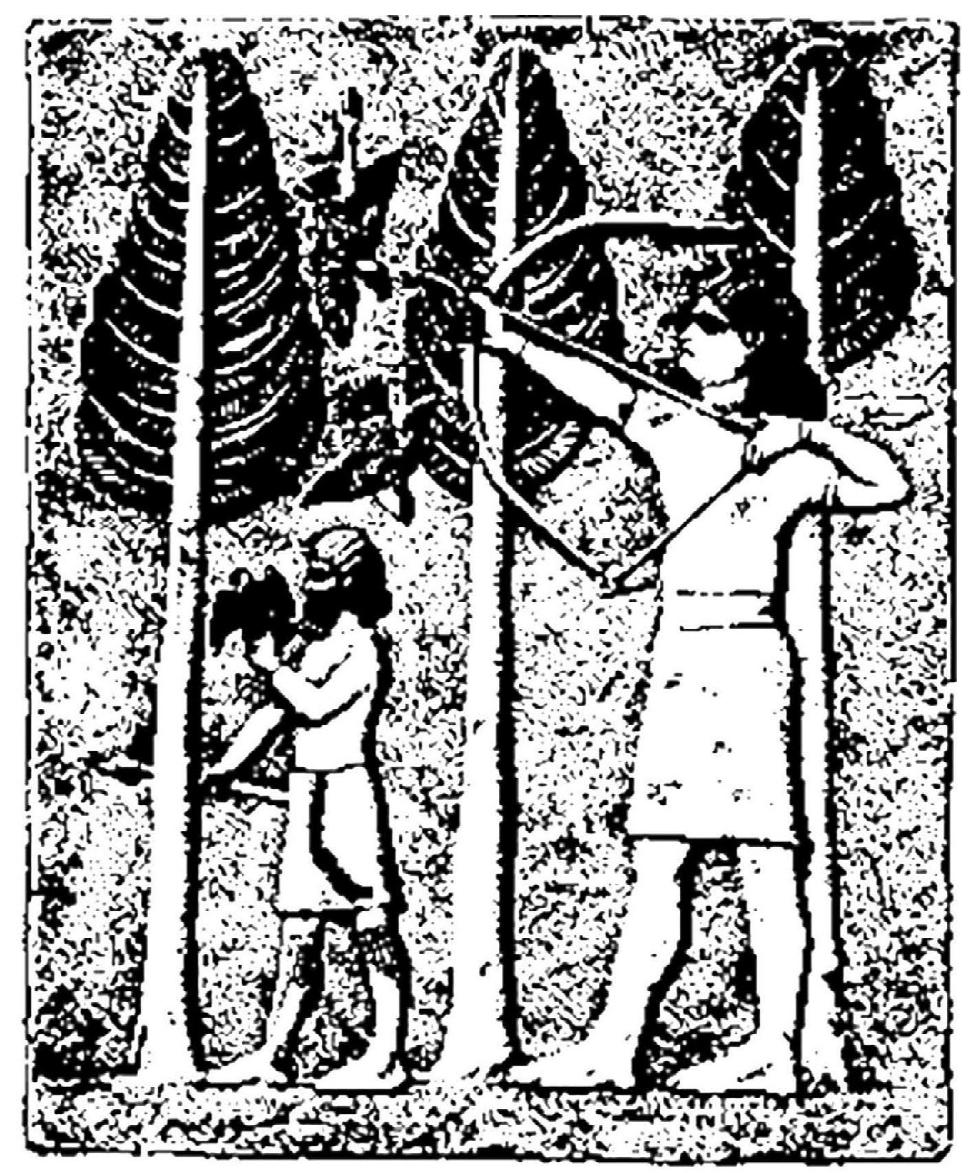

Рис. 2. Ассирийский барельеф времен Саргона II

Fig. 2. Assyrian bas-relief of the times of Sargon II

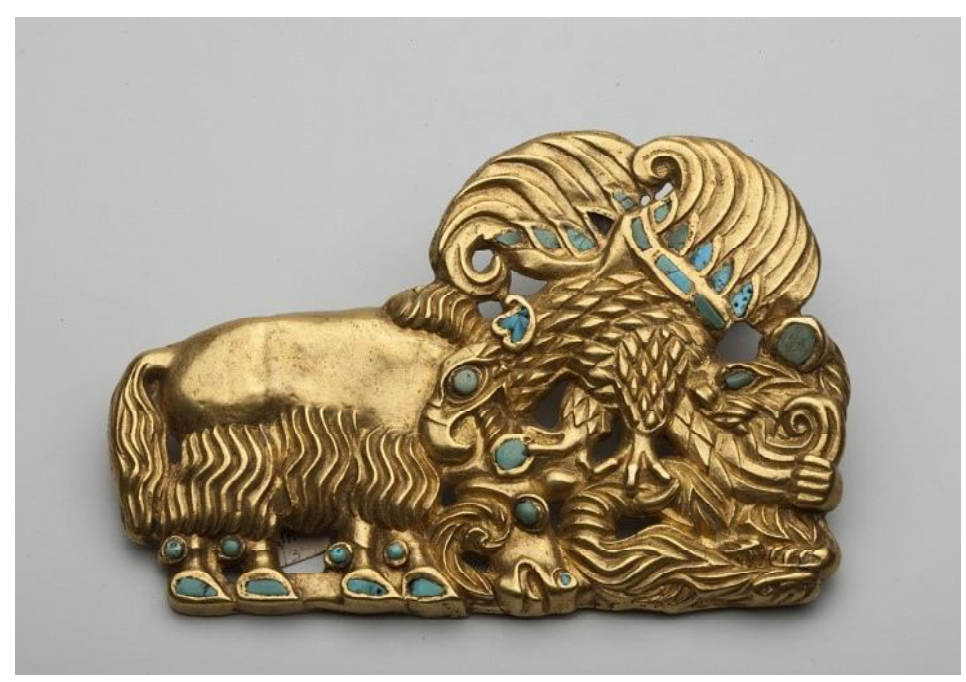

Рис. 3. Пряжка-застежка из Сибирской коллекции Петра I

Fig. 3. Buckle-clasp from the Siberian collection of Peter I 
С.И. Лукьящко. О времени появления практики использования ловчих птиц в традиционных культурах Евразии

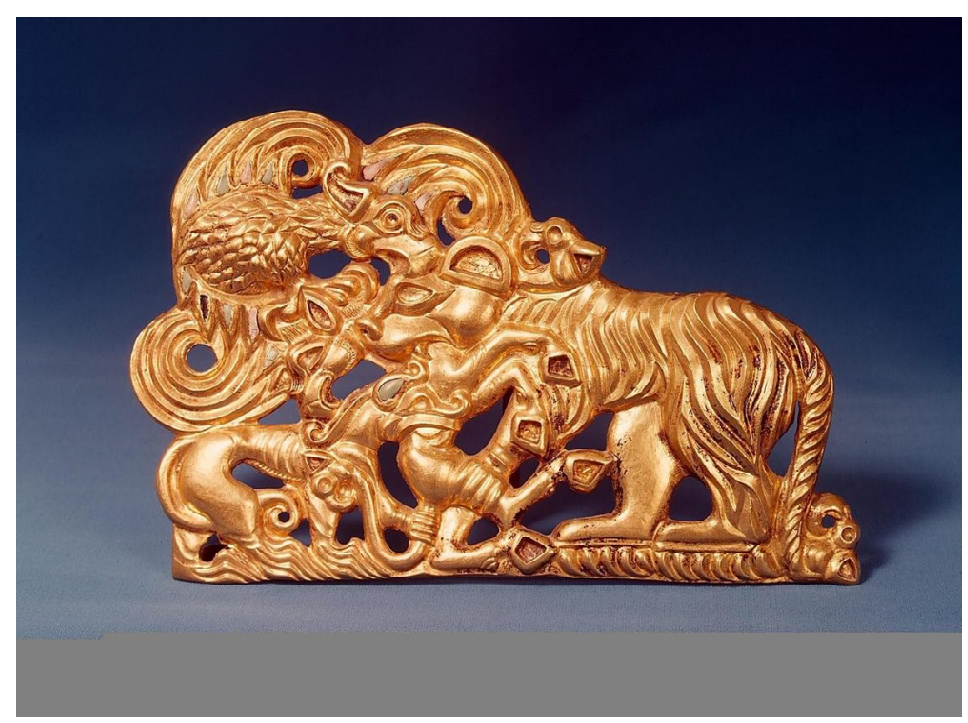

Рис. 4. Пряжка-застежка из Сибирской коллекции Петра I

Fig. 4. Buckle-clasp from the Siberian collection of Peter I

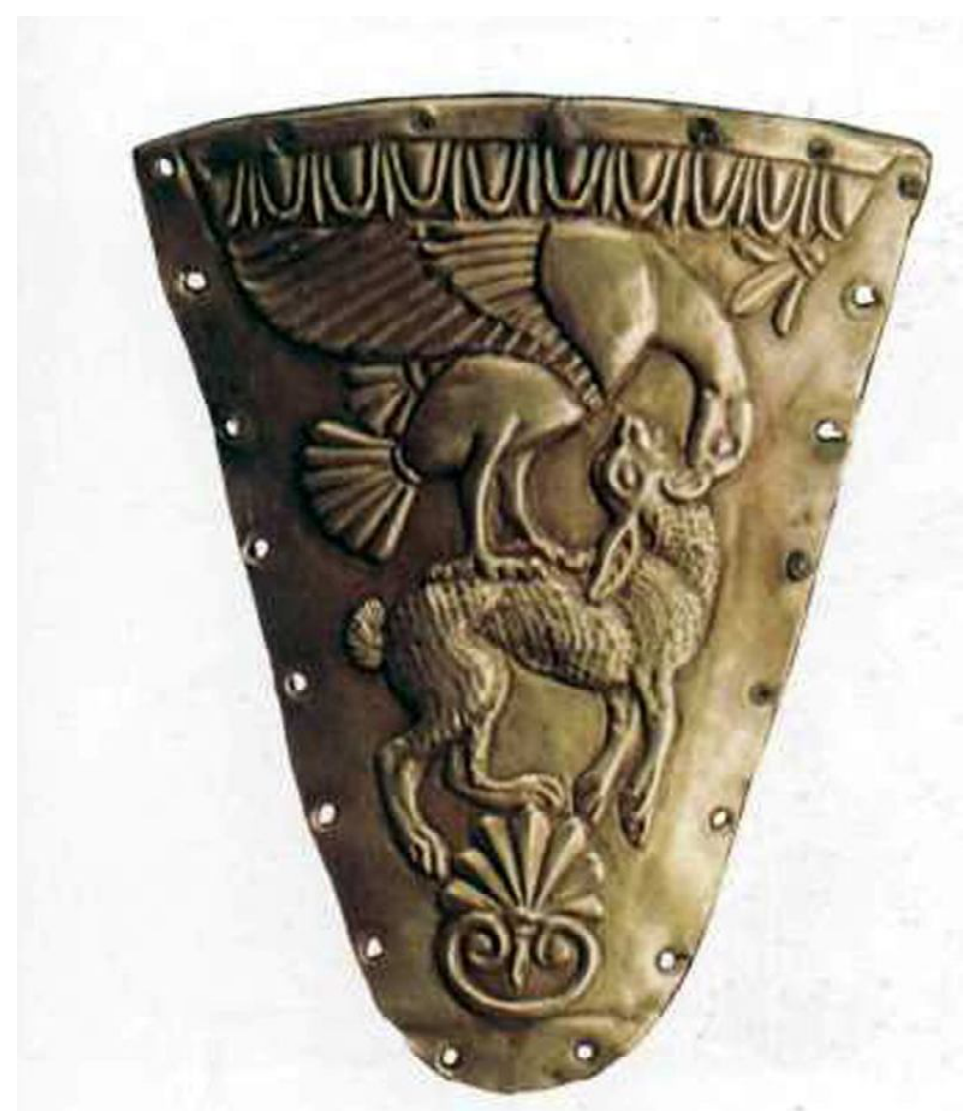

Рис. 5. Пластина-обивка ритона (4-й Семибратний курган)

Fig. 5. Plate-upholstery of the rhyton. Semibratniy Barrow 4 


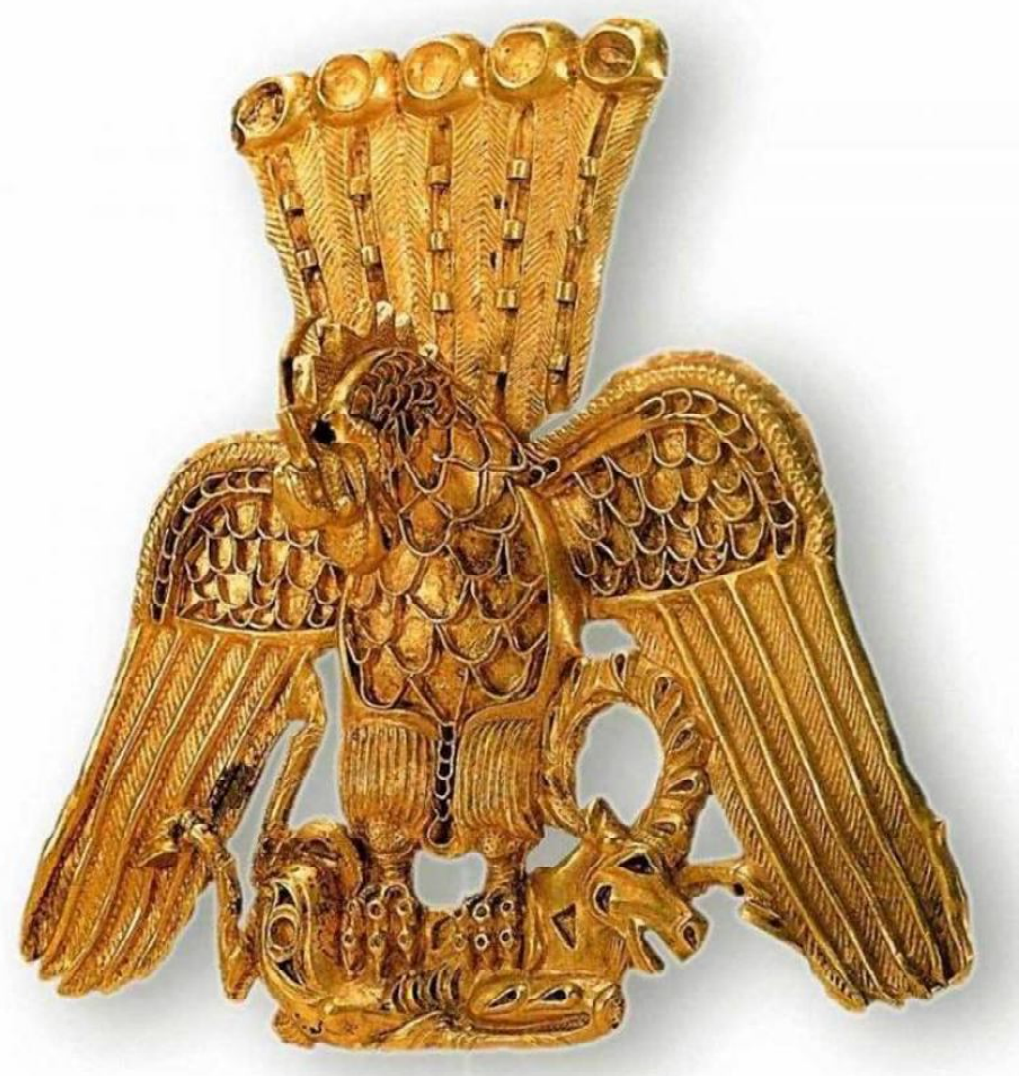

Рис. 6. Украшение из Сибирской коллекции Петра I

Fig. 6. Decoration from the Siberian collection of Peter I 


\section{СПИСОК ЛИТЕРАТУРЫ}

1. Байгушева, В. С. Археологические сведения о степной фауне позвоночных Приазовья / В. С. Байгушева // Античная цивилизация и варварский мир : материалы 8-го археол. семинара (Краснодар, 1315 июня 2001 г.). - Краснодар : Изд-во Краснодар. гос. акад. культуры, 2002. - С. 109-116.

2. Байгушева, В. С. Орнитофауна и териофауна Приазовья по материалам археологических раскопок / В. С. Байгушева // Историко-археологические исследования в г. Азове и на Нижнем Дону. Вып. 22. - Азов : Изд-во Азов. музея-заповедника, 2006. - С. 341-356.

3. В кургане Жати-Тобе в Жамбульской области был погребен золотой человек. - 19.02.2013. Электрон. текстовые дан. - Режим доступа: http:// www.dailynews.kz/culture/v-kurgane-zheti-tobe-vzhambylskoj-oblasti-byl-pogreben-zolotoj-chelovek (дата обращения: 01.03.2019). - Загл. с экрана.

4. Добровольская, Е. В. Археозоологические исследования Фанагории (2005-2008 гг.) / Е. В. Добровольская // Х Боспорские чтения. Боспор Киммерийский и варварский мир Причерноморья в эпоху античности и средневековья. Актуальные проблемы. - Керчь : Керченска миська друкарня, 2009. - C. 113-118.

5. Лукьяшко, С. И. Охота степных кочевников Причерноморья в раннем железном веке / С. И. Лукьяшко // Нижневолжский археологический вестник. - 2019. - Т. 18, № 2. - C. 62-74. - DOI: https:// doi.org/10.15688/nav.jvolsu.2019.2.4.

6. Охота с ловчими птицами: возвращаясь к истокам. - Электрон. текстовые дан. - Режим доступа: https://astana.zagranitsa.com/article/1608/ okhota-s-lovchimi-ptitsami-vozvrashchaias-k-istoka (дата обращения: 14.05.2020). - Загл. с экрана.

7. Руденко, С. И. Сибирская коллекция Петра I / С. И. Руденко. - М. ; Л. : Изд-во АН СССР, 1962. 52 c. - (Серия: Археология СССР. Свод археологических источников / под общ. ред. акад. Б. А. Рыбакова ; вып. Д 3-9).

\section{REFERENCES}

1. Baygusheva V.S. Arkheologicheskie svedeniya o stepnoy faune pozvonochnykh Priazovya [Archaeological Information About the Steppe Fauna of Vertebrates of the Azov Region]. Antichnaya tsivilizatsiya $i$ varvarskiy mir: materialy 8-go arkheol. seminara (Krasnodar, 13-15 iyunya 2001 g.) [Ancient Civilization and the Barbarian World. Materials of the $8^{\text {th }}$ Archaeological Seminar (Krasnodar, June 13-15, 2001)]. Krasnodar, Izd-vo Krasnodarskoy gosudarstvennoy akademii kultury, 2002,pp.109-116.

2. Baygusheva V.S. Ornitofauna i teriofauna Priazovya po materialam arkheologicheskikh raskopok [Ornithofauna and Theriofauna of Azov Region Based on Archaeological Excavations]. Istorikoarkheologicheskie issledovaniya $v$ g. Azove $i$ na Nizhnem Donu. Vyp. 22 [Historical and Archaeological Research in the City of Azov and the Lower Don. Iss. 22]. Azov, Izd-vo Azovskogo muzeyazapovednika, 2006, pp. 341-356.

3. Vkurgane Zhati-Tobe $v$ Zhambulskoy oblasti byl pogreben zolotoy chelovek [A Gold Man Was Buried in the Zheti-Toba Mound in Zhambyl Region]. February 19, 2013. URL: http://www.dailynews.kz/ culture/v-kurgane-zheti-tobe-v-zhambylskoj-oblasti-bylpogreben-zolotoj-chelovek (accessed 1 March 2019).

4. Dobrovolskaya E.V. Arkheozoologicheskie issledovaniya Fanagorii (2005-2008 gg.) [Archeozoological Studies of Phanagoria (2005-2008)]. $X$ Bosporskie chteniya. Bospor Kimmeriyskiy $i$ varvarskiy mir Prichernomorya v epokhu antichnosti $i$ srednevekovya. Aktualnye problemy $\left[10^{\text {th }}\right.$ Bospor Readings. Bosporus Cimmerian and the Barbaric World of the Black Sea in the Era of Antiquity and the Middle Ages. Current Issues]. Kerch, Kerchenska miska drukarnya, 2009, pp. 113-118.

5. Lukyashko S.I. Okhota stepnykh kochevnikov Prichernomorya $\mathrm{v}$ rannem zheleznom veke [Hunting of the Steppe Nomads of the Black Sea in the Early Iron Age]. Nizhnevolzhskiy arkheologicheskiy vestnik [The Lower Volga Archaeological Bulletin], 2019, vol. 18, no. 2, pp. 62-74. DOI: https://doi.org/10.15688/nav.jvolsu. 2019.2.4.

6. Okhota s lovchimi ptitsami: vozvrashchayas $k$ istokam [Hunting with Hunting Birds: Returning to the Origins]. URL: https://astana.zagranitsa.com/article/ 1608/okhota-s-lovchimi-ptitsami-vozvrashchaias-kistoka (accessed 14 May 2020).

7. Rudenko S.I. Sibirskaya kollektsiya Petra I [Siberian Collection of Peter 1]. Moscow, Leningrad, Izd-vo AN SSSR, 1962. 52 p. (Seriya: Arkheologiya SSSR. Svod arkheologicheskikh istochnikov [Series: Archaeology of the USSR. Code of Archaeological Sources], iss. D 3-9). 


\section{АРХЕОЛОГИЯ РАННЕГО ЖЕЛЕЗНОГО ВЕКА}

\section{Information About the Author}

Sergey I. Lukyashko, Doctor of Sciences (History), Professor, Head of the Department of Archaeology and History of Culture, Don State Technical University, Gagarina Sq., 1, 344000 Rostovon-Don, Russian Federation; Head of the Laboratory of Archaeology, Federal Research Centre The Southern Scientific Centre of the Russian Academy of Sciences, Chekhov St, 41, 344006 Rostov-onDon, Russian Federation, sciphica@ssc-ras.ru, https://orcid.org/0000-0001-8085-4652

\section{Информация об авторе}

Сергей Иванович Лукьяшко, доктор исторических наук, профессор, заведующий кафедрой археологии и истории культуры, Донской государственный технический университет, пл. Гагарина, 1, 344000 г. Ростов-на-Дону, Российская Федерация; заведующий лабораторией археологии, Федеральный исследовательский центр Южный научный центр РАН, просп. Чехова, 41, 344006 г. Ростов-на-Дону, Российская Федерация, sciphica@ssc-ras.ru, https://orcid.org/0000-0001-8085-4652 